\title{
Health System Organization and Governance in Canada and Australia: A Comparison of Historical Developments, Recent Policy Changes and Future Implications
}

Organisation et gouvernance des systèmes de santé au Canada et en Australie : comparaison du parcours historique, des changements politiques récents et des répercussions à venir

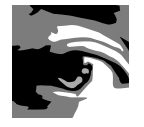

by DONALD J. PHILIPPON, PHD, CHE

Professor, Strategic Management and Health Policy

School of Business

University of Alberta

Edmonton, $A B$

JEFFREY BRAITHWAITE, MBA, PHD

Professor, School of Public Health and Community Medicine

Faculty of Medicine

University of New South Wales

Sydney, Australia 


\section{Abstract}

The Canadian and Australian health systems have evolved in very similar ways. Recent policy changes in each country, however, suggest a growing divergence with respect to governance. This paper traces the origins and key milestones in the evolution of governance models, with a selective focus on two provinces in Canada (Saskatchewan and Alberta) and the state of New South Wales in Australia. While divergent models seem to be manifesting, many similar underlying features remain. We assess these developments and comment on the current patterns of organization and governance, both to provide insights on future directions and to suggest what the two countries might learn from each other.

\section{Résumé}

Les systèmes de santé au Canada et en Australie ont évolué de façon similaire. Toutefois, les récents changements de politiques dans les deux pays portent à croire qu'il y a une divergence grandissante quant à la gouvernance. L'article relate les origines et les principales étapes des modèles de gouvernance respectifs des deux pays, plus précisément ceux de deux provinces canadiennes (la Saskatchewan et l'Alberta) et ceux de l'État de la Nouvelle-Galles du Sud, en Australie. Bien que les modèles semblent divergents, il existe entre eux plusieurs caractéristiques similaires. Nous évaluons leur progression et commentons les modèles d'organisation et de gouvernance actuels, à la fois pour donner un aperçu des orientations à venir et pour dégager ce que ces pays peuvent apprendre l'un de l'autre.

\section{The objectives of this paper are to Review SOMe of the Key Mile- stones in the evolution of health system organization and governance in 1 Canada and Australia, to identify recent policy developments affecting the} governance models and to provide insights into future directions and what the two countries can learn from each other. Two Canadian provinces, Saskatchewan and Alberta, and one state in Australia, New South Wales, were selected for detailed comparisons. These provinces and state were chosen largely because of the key role they have played in developing new organizational models in their respective countries, and thus help illustrate the pattern of development.

Canada and Australia are both federated systems with a similar division of powers between the central and provincial or state governments on matters pertaining to health. The British North America Act of 1867 and the Commonwealth of Australia Constitution Act of 1900, both Acts of the British Parliament, placed the major responsibility for the delivery of health services at the provincial or state government 
level. In each country, the governance models are in effect creatures of provincial and state laws. The founders of the Canadian federation deliberately created a highly centralized system of government, with residual powers being vested at the federal level. This was not the intention in Australia, where by implication, residual powers were left to the states (Gray 1991). Accordingly, one would expect more centralized characteristics for health governance in Canada, but quite the opposite has occurred. As will be discussed later, a constitutional amendment and the five-year Australian Health Agreements have consolidated increased Commonwealth powers, while in Canada, provinces continue to dominate, with new models emerging for national initiatives.

Both countries have mixed public-private health systems in a pluralist, multistakeholder structure with power shared between the two levels of government. Centrally, there is the federal government (Canada) and the Commonwealth government (Australia). At the next level, there are states, provinces or territories: 10 provinces and three territories for Canada, and six states and two territories for Australia. The local or municipal government level plays a much smaller role in both systems.

\section{Evolution of Health Systems}

\section{Origins of the systems}

In Canada, at the outset, provinces relied heavily on the organization of municipalities to provide local services. The earliest forms of public governance in the Canadian health system grew out of creations at the municipal government level. Both countries had a strong tradition of religious or charitable organizations providing hospital services that preceded public institutions. The province of Saskatchewan, formed in 1905, had 297 functioning municipalities by 1916. In trying to meet the needs of their residents, municipalities began Municipal Doctor Programs, and by 1944 there were at least 101 such programs (Houston 2002). Similar programs, although on a more limited scale, also developed in the neighbouring provinces of Alberta and Manitoba (Gray 1991).

However, from the beginning, the limitations of having single municipalities provide certain services were recognized. Hospital construction was a case in point. In 1916, both Saskatchewan and Alberta passed their first municipal hospital legislation. Interestingly, these actions had been triggered in part by developments in the border community of Lloydminster, where the editor of the local newspaper, D.G. Tuckwell, a new arrival from Australia, promoted the idea of a union hospital. The legislation allowed two or more municipalities geographically adjacent to each other to form a union hospital board (Roemer 1955). Amendments to legislation over the next two decades not only provided a legislative base for these hospital plans, but also empowered municipal councils to levy a personal tax for hospital services. Taylor (1978) notes, "this appears to be the first instance in which statutory authority was granted for the levying of a personal tax for health services in Saskatchewan and, indeed, in 
Canada." Union hospital boards assumed responsibility for raising funds through taxation and the issuance of debentures to construct hospitals.

In the absence of a universal publicly funded system at that time, these hospital boards also assumed responsibilities for operating costs. The model of governance with board members chosen from the communities they served became the dominant mode of hospital governance throughout Canada. This model was also applied in other health sectors. In 1928, legislation in Saskatchewan allowed for the organization of public health districts consisting of at least eight municipalities (Roemer 1955). Commenting on the emergence of local governance models, Roemer (1955) states:

It is no accident that so much joint action by municipalities to finance health services was undertaken. Here was a need that came close to the hearts and, indeed, the pocketbooks of rural people. Faced with life and death issues, rural municipalities recognized their inability singly to meet health needs and undertook various agreements regarding both preventive and curative services, designed to protect the health of their families that cut across municipal lines.

The early Australian governance developments were very different. Municipal or local governments played only a small role in providing healthcare. After colonial settlements in the late 18th century, hospitals slowly emerged in the 19th, financed chiefly by subscription fees. Doctors, like their counterparts in England and Canada, offered services as entrepreneurs, largely to the wealthy. Charity hospitals were initiated and run by religious institutions, with a charter to treat the sick poor. Governance was contested between doctors on the one hand, who became honorary practitioners at hospitals in order to control admissions and treat their patients, and the religious or charitable organizations, often in the form of Friendly Societies, who administered the hospitals. Green and Cromwell (1984) note that the Friendly Societies obtained their revenue from subscriptions made by employed men, with coverage for members who might be temporarily unemployed, became ill or suffered a death in the family. Persons of wealth were treated at home by doctors on the basis of capacity to pay (McCoppin 1974; Inglis 1980; Horsburgh 1976).

In these early years, doctors were accorded the right to admit their private, fee-paying patients to public or charitable hospitals, who then charged patients for their accommodation (Crichton 1998). Hospital boards and doctors both benefited from a system that split responsibility and allowed private and public patients access to public facilities. Hospital boards of various forms emerged in Australian states, eventually reporting to health departments or hospital commissions. The Commonwealth slowly became involved through its taxation capacity in co-funding increasingly expensive acute care.

In the 19th and first half of the 20th century, however, the involvement of the Commonwealth government in health matters was very limited. This situation began 
to change with the establishment of a federal health department in 1921, which had a mandate to provide health services in cooperation with the states. A 1946 constitutional amendment gave the Commonwealth wide concurrent powers in health policy. The Commonwealth soon became the dominant player on matters pertaining to physicians and pharmaceutical policy. Hospital matters, including arrangements with medical staff, and non-general practice community services remained in state hands. At about the same time in Canada, the Royal Commission on Dominion-Provincial Relations (Rowell-Sirois Commission) recommended that health services remain a provincial responsibility (Gray 1991).

Looking at the health delivery systems within the provinces and states, very different patterns are evident from the earliest days. In Canada, provinces focused their efforts on removing financial barriers for citizens to access care and on creating subprovincial organizations to deliver services while generally not becoming directly involved in service provision. In Australia, however, the tradition was quite different, with states taking more direct involvement in providing services. States assumed a high level of responsibility for hospital services. In fact, Tasmania "nationalized" its hospitals in 1918, and Queensland took the same step in 1936. Thus, early governance models in Australia were characterized by an increasing degree of state government involvement in management. New South Wales and Victoria had a system of public hospitals run by independent boards until 1921, but more than half of the capital and operating expenses were covered by the state. In the other states, governments provided an ever-larger subsidy and consequently assumed an enhanced role, directly or through indirect influence, in management (Gray 1991).

\section{Health boards and public financing}

The effects of worldwide economic depression, coupled with a devastating drought in the 1930s, caused some major rethinking of the early governance models in Saskatchewan, where municipal-based models had been pioneered. Several provincial initiatives were introduced to assist municipal plans, but the main financial responsibility continued at the local level. Disparities in wealth among municipalities led to wide variation in the availability of health services, pointing to the need for a provincial program that provided financial stability while promoting greater equity in access to services and more quality control (Roemer 1955).

Emerging from the economic and social environment of the 1930s, a new political party, the Cooperative Commonwealth Federation (CCF), elected its first members in the 1934 Saskatchewan election and formed the government in 1944. From the outset, the CCF, led by T.C. Douglas, took up the cause of introducing publicly funded health insurance. On assuming government, Douglas took on the dual role of premier and minister of health. He rapidly implemented a hospital plan, first introducing a plan 
for individuals receiving social assistance in 1945, and then a universal, provincewide Hospital Services Plan in 1947 (Taylor 1978). Premier Douglas's decision to go it alone, before agreement was reached at the federal-provincial level on funding, was a major gamble for an economically challenged province. But as Taylor (1978) indicates: "A social idea had been translated into an operating reality; the first universal hospital insurance program in North America had been launched. For Saskatchewan there was no turning back."

The adoption of a universal hospital plan in Saskatchewan was quickly followed by similar plans in other provinces (Alberta, 1950; British Columbia, 1952). Newfoundland, which had entered Confederation only in 1949, brought with it a hospital services plan covering almost half its population. By the end of 1950, four provinces had hospital plans, although only those in Saskatchewan and British Columbia covered the entire population (Taylor 1978). The long-standing discussions with the federal government, which had collapsed in 1945, were reopened and finally concluded in 1958 with the passage of federal legislation providing a cost-sharing program for hospital plans. By 1961, all provinces had hospital plans in place.

Initially, the introduction of the Saskatchewan Hospital Services Plan (SHSP) did not affect the governance model, but two key developments would prove to have far-reaching effects over the years. First, the provincial government became the chief source of income for all hospitals, with the role of hospital boards largely confined to cost-sharing on capital costs. Second, in 1947 legislation empowered the minister of health to define a union hospital district, a step towards overall planning of hospital services (Roemer 1955). Notably, in the lead-up to the SHSP, Dr. Henry Sigerest, from Johns Hopkins University, Baltimore, Maryland, was commissioned to provide a series of explicit objectives and priorities on health issues for the new CCF government (Taylor 1978). His 1944 report recommended the establishment of health districts comprising many municipalities. These administrative units, or regions, were to provide the framework for preventive as well as curative services through district hospitals and rural health centres. Provincewide health insurance was recommended to underpin financing of medical care.

With hospital financing secured in Saskatchewan and new provincial grants to assist with construction, a period of increased development of hospital services emerged (Taylor 1978). Similar patterns were observed in other provinces, leading to questions about governance models based strictly on representation from participating municipalities. A mix of board structures began to emerge in all provinces from the 1950s through 1980. Boards for community hospitals generally preserved their linkages to municipalities; however, larger regional facilities and the major tertiary centres tended to evolve with provincially appointed boards.

While the costs of hospital services were brought under publicly funded plans across Canada by 1961, physician services remained privately funded for several more 
years. Again, Saskatchewan led the way with the introduction of a prepaid, publicly administered medicare plan in 1962. However, this initiative triggered a bitter, provincewide doctor's strike lasting for 23 days. The historic Saskatoon Agreement that ended the strike paved the way for the pattern of physician involvement in publicly funded plans that later emerged across Canada. Essentially, the payment mechanisms for physicians recognized their contractual autonomy from government (Marchildon 2006). The concept of physicians providing services as independent practitioners has continued to the present time in all provinces.

Funding for early hospitals in Australia was an inchoate mix of charitable contributions, fees for services and tax-supported subsidies. In the early years of the 20th century, the Labor party began to argue for the nationalization of hospitals and free care for all (Gray 1991). By the 1920s and 1930s, community hospitals developed along American lines. Private wards were included in public hospitals, and physicians were able to charge fees to non-public patients. In the 1940s, plans were being hatched for a national health service; the ultimate goal was a free and universal system.

While the system of philanthropic funding that had operated since the earliest days was increasingly challenged, there was major resistance to the idea of a government-sponsored system from the medical profession and the Friendly Societies. Despite the resistance, both New South Wales and Tasmania took bold steps. In New South Wales, Health Minister Fred Flowers championed the universal rights of all to healthcare in preference to the institutionalized dependence on charity (Gray 1991; Crichton 1998). He organized a wide variety of institutional and community-based services financed from state revenues (Crichton 1998). Tasmania took the boldest step of all when it eliminated the charitable basis for the provision of hospital services and took control of hospital boards in 1918, making medical need the predominant basis for access to care (Gray 1991).

Resistance to government-sponsored, universal systems of health insurance continued, but after the Second World War, constitutional amendments gave the Commonwealth powers to introduce a subsidized, contributory scheme. Existing insurance organizations were used in what was essentially a privately organized insurance scheme, known as the Page plan, after the sponsoring Commonwealth minister for health who initiated it. This plan maintained a tiered system without pretense of universality. Eventually, in 1974, following the election of a Labor government, Medibank, a universal health insurance scheme, was instituted (Scotton and Macdonald 1993). Medibank made treatment in public hospitals free at the point of delivery. Doctors treating public patients became either salaried or sessional staff, and the costs were shared between the Commonwealth, states and territories, and patients (the latter paying $15 \%$ of the scheduled fee).

However, with a change of government in 1976 to a more right-of-centre party, the Liberal-Country Party, Medibank underwent various modifications until Labor 
was re-elected in 1983. Medicare, an updated and reformed version of Medibank, was then enacted into legislation. Doctors protested, especially in New South Wales. They perceived this program, along with other political actions of governments to manage their economic power, as a scheme to erode their autonomy, rights and incomes. A series of doctors' strikes ensued. Eventually the government agreed to a package of measures that were designed to maintain or enhance medical income levels. The underlying ideological battle had been about a subsidized market system underwritten by government versus a government-controlled system incorporating universal coverage. Australia's approach was a compromise between what doctors were prepared to accept, particularly in terms of their income levels, and what government was prepared to accept, particularly in respect of financial commitments. Underneath it all, the issue of importance was who controlled what, and how.

\section{Health boards and regionalization}

By the late 1980s, existing governance models in Canada came under increased scrutiny. Kouri (2002) notes that while models of regionalization vary markedly across Canadian provinces, four specific objectives were behind the transition to a regional mode: (1) the integration of services along a wider continuum of care, (2) a greater focus on upstream strategies such as health promotion and prevention, (3) more meaningful public participation and (4) more appropriate governance. A fiscal imperative underpinned many of those objectives. Marchildon (2006) notes that structural reform through regionalization in Saskatchewan was pursued as a means to find savings through major service rationalization, integration and coordination. Similarly in Alberta, Philippon and Wasylyshyn (1996) observe that major cost reductions accompanied the introduction of regionalization in that province.

Most provinces commissioned major studies to look at their health systems. A common theme emerging from these studies was the need to look at some economies of scales through consolidation. By the mid-1980s, each province had systems of hospital boards, public health boards, mental health boards and long-term care boards. In 1990 there were more than 900 hospitals in Canada, usually located on a single site and each with its own board of directors (Decter 2000). The Premier's Commission on Future Health Care for Albertans (1989) (known as the Rainbow Report) recommended that the more than 200 existing governance structures be consolidated into nine autonomous administrative areas accountable through Health Authorities (Premier's Commission 1989). The Future Directions Report in Saskatchewan (Saskatchewan Commission 1990) recommended creating 15 comprehensive Health Service Divisions to replace over 400 local boards. The Alberta report was met with strong negative reaction from rural areas and existing boards, who argued that such a move would erode local decision-making. The Alberta government's initial response 
recognized the need to move cautiously on this recommendation.

In the early to mid-1990s, initiatives to create regional structures began to accelerate. Quebec had introduced elements of a regional structure in the early 1970s with regional councils, but these had limited responsibilities (Pineault et al. 1993). In 1992, following the recommendations of the Rochon Commission, the regional councils were replaced with regional boards (Pineault et al. 1993). New Brunswick eliminated 51 separate hospital boards in 1992, replacing them with eight regional boards (PEI System Evaluation Project 1997) for hospital and nursing home services. The first comprehensive health boards were established in Prince Edward Island in 1993 with five regional boards vested with very broad responsibilities for health and community services (PEI System Evaluation Project 1997). Saskatchewan implemented a regional system with 33 district boards in 1993, and Alberta did likewise in 1994 with 17 regional boards. The Saskatchewan and Alberta systems provided the most comprehensive range of services of any of the provinces with regional boards (except for PEI). Even these boards did not cover the entire spectrum of health services as payments to physicians, drug plans and specialized cancer and mental healthcare were not included.

In both Saskatchewan and Alberta, the number of regions or districts initially established was much higher than their respective commission reports had recommended. This difference clearly reflected what was seen to be politically feasible as a first step, and public outcry continued about the erosion of local input and citizen engagement. The furor was understandable, as over 200 boards were replaced in Alberta and over 400 in Saskatchewan by the new structures. While in both provinces the initial district/regional boards were solely appointed by the minister, there were commitments to look at different models in the future.

By the late 1990s, all provinces except Ontario moved to create regional health boards. These initiatives were intended to devolve authority from provincial health ministries to regional bodies that would have some measure of discretion in the allocation of health resources. In fact, these boards became operative when provincial governments were implementing tough cost-cutting measures (Maioni 2004).

In Australia, the predominant governance structure of a single board for each hospital started to come under serious question in the 1970s. There were also major variations across states and territories in respect of responsibilities, legislative powers, rights, obligations and composition of boards (Jamieson 1980). In the 1980s, the idea of regionalization via new, publicly funded Area Health Service models covering acute, preventive and mental health services for a defined population gained prominence. By the early 1980s there were 1,065 hospitals in Australia, of which about two-thirds were publicly funded and one-third privately operated (AIHW 2004). Many inquiries took place at various points, usually out of concern over how healthcare was organized and funded. New South Wales led the way in regionalization through the creation of 23 Area Health Service regions in 1986, with each region having an appointed board. 
In the next decade there was a strong shift in other states and territories away from stand-alone (or "atomized") boards, as Dwyer and Leggat (2002) call them, to various forms of regional systems.

Dwyer and Leggat note that across Australia's states and territories, different forms of regionalization emerged and there was intermittent chopping and changing, possibly in a search for the ideal structure to match a particular health jurisdiction's needs. Regional health authorities were abandoned in Queensland after eight years with consolidation at the state level; similar state consolidation occurred in Western Australia and Tasmania. Victoria never embraced a full regional system but developed a series of service networks in the mid-1990s, which were further restructured in 2000 into metropolitan health services (Government of Victoria 2000). South Australia's major Generational Health Review (Government of South Australia 2003) recommended moving towards a regional system in Adelaide (rural areas had regionalized in 1995). The boundaries of New South Wales' Area Health Services were restructured on two major occasions. Overall, restructuring in Australia has tended to be associated with changes in ministers, governments or directors-general of health departments. Often a regionalized structure was viewed as a political reaction rather than a carefully planned strategy (Stoelwinder and Viney 2000; Dwyer and Leggat 2002). An added complexity was that general practitioners were organized into regional divisions starting in the 1990s. These GP Divisions are funded and administered at the Commonwealth level separately from regionalized acute services in the states and territories, thus adding further challenges in achieving a streamlined, coordinated, integrated regional health system.

\section{Recent Policy Changes Affecting Governance of the Health Systems}

\section{Ongoing structural change}

One of the objectives of regionalization, both in Canada and in Australia, was to achieve greater efficiency in the use of health resources and thereby reduce cost escalation. With some minor exceptions in the initial years, however, healthcare costs have continued to climb at rates substantially greater than that of inflation. This factor, along with ongoing issues centred on defining the correct regional boundaries, led many Canadian provinces and Australian states into various rounds of consolidation. In Saskatchewan the 32 districts introduced in 1993 were reduced to 12 regions in 2002. Similarly, in Alberta, the 17 regions introduced in 1994 were reduced to nine in 2003. In Australia, New South Wales changed the boundaries of its Area Health Services: in 1986, 23 Area Health Services were established; by 1988 this number was reduced to 17 , and by 2004 it was reduced to eight. 
A sudden turnabout in health policy in Canada occurred in 2005 when Prince Edward Island, the smallest province, dissolved all regional boards. While the decision was an abrupt change, it needs to be placed in context. In effect, there were six governance entities, including the Department of Health and Social Services itself, administering a health system that included only seven hospitals for a total population of 140,000. Government took over the administration of health and social services with all staff becoming government employees. The plan eliminates all regional boards but does retain advisory boards for the five community hospitals (D. Riley, Deputy Minister, PEI Department of Health, August 30, 2005, personal communication). In 2008, New Brunswick also began to retreat from a regional structure by consolidating eight Regional Health Authorities down to two and creating a New Brunswick Health Council. Health Minister Murphy argued this change would remove barriers to patient care that have existed between regions, direct more the health care budget into patient care, reduce administrative costs and increase the performance of the system (Murphy 2008). But the most dramatic directional change came from Alberta in May 2008 when Health Minister Ron Liepert announced the elimination of all existing Health Boards replacing them with a new Alberta Health Services Board. As part of the transition, the new board assumes responsibility for each of the existing nine regions and will assume the functions of the Alberta Cancer Board, the Mental Health Board and the Alberta Alcohol and Drug Abuse Commission. The new board appointed by the minister is responsible for health services delivery for the entire province (Alberta Health and Wellness 2008). The future of any form of a regional structure in the delivery of health services is uncertain. The arguments for dismantling the regional boards in Alberta, like in New Brunswick, centre around the need to remove barriers for patients created by regional structures, the need for improved system performance and the intention to reduce administrative costs.

The most significant policy development in Australia relative to regional-level governance in recent years has been the decision in New South Wales to disestablish Area Health Service boards. In July 2004, in the policy document Planning Better Health Reforms (NSW Health 2004a), the minister for health announced an increased focus on providing a more efficient health system. To that end, the 17 Area Health Services were amalgamated into eight area administrations (along with an ambulance service, cancer institute, justice health service and specialized children's health service), and these are directly accountable to the Department of Health (NSW Health 2004a). Under the new system, the eight regional chief executives are directly accountable to the director-general. In announcing this change, the minister argued that one of the key principles of the reforms was to provide clinicians, health consumers and local communities with a greater say in the planning and delivery of health services at both the state and local levels. The restructuring plan also included establishing Area Health Advisory Councils (AHACs) in each of the eight areas and 
the creation of a new Health Care Advisory Council to serve as the peak clinical and community advisory body to the minister (NSW Health 2004b).

\section{Public participation}

Many commentators note that one of the objectives of regionalization in Canada was to achieve enhanced public participation in decision-making to reflect regional health needs (OHA 2002; Kouri 2002; Marchildon 2006). This emphasis on public participation does not appear to have received the same attention in the evolution of health systems in Australia.

The issue of elected versus appointed board members has been a matter of much deliberation in Canada, but not to the same extent in Australia. While initially boards in Canada could reasonably state that they represented the interests of their communities, this claim became questionable with regional boards serving larger populations and geographical areas. Moreover, the intent to have regional boards make decisions on how best to use available resources raises questions about the desirability of having individuals on boards who are seen to represent the interests of specific communities. Lomas (1997) notes that each devolved authority in Canada has had to come to its own resolution of the inherent conflict among its provincial government's expectations, provider interests and citizens' needs and wants. These diverse interests have led boards variously down the paths of community empowerment, system rationalization and expenditure reductions. Noting the inherent conflict among these considerations, Lomas argues that most boards have given priority to system rationalization.

Saskatchewan and Alberta both introduced their regional systems with fully appointed boards in 1992 and 1994, respectively, with the promise to consider other models for the creation of boards in the future. Both then moved to a system of partially appointed and elected boards. This occurred in Saskatchewan in 1995, with two-thirds of board members being elected; this system remained in effect until 2002. In Alberta, a similar approach was introduced in 2002 but was discontinued in 2003. Both provinces moved back to fully appointed boards when they reduced the number of regions. Quebec replaced elected boards with appointed boards in 2002 and a CEO directly appointed by the minister and accountable to both the minister and the board (Levine 2004). As noted above, Prince Edward Island has eliminated regional boards and consolidated decision-making at the provincial government level.

The experience in Saskatchewan, with its partially elected boards in the period 1995 to 2002, provides some interesting observations. Most noteworthy is that community interest, as expressed both by candidates and voter turnout, was low. In fact, voter turnout declined from 35\% in 1995 (Lomas 1997) to 10\% in 1999 (Lewis et al. 2001). Lewis and colleagues surveyed district board members in 1997. Most (83\%) felt devolution had resulted in increased local control and better-quality decisions. 
Many respondents (76\%) felt boards were legally responsible for things over which they had insufficient control. The majority (62\%) felt that they were too restricted by rules laid down by the provincial government.

By comparison, the issue of public participation in governance and decision-making in health systems has received much less attention in Australia. Given the tradition of more state involvement in the operation of the health system, public expectations are considerably different. The elimination of boards in New South Wales in 2004 received little public attention, for example. It is not clear why this might be the case, but perhaps Australians are more apathetic than Canadians about reform of public institutions and structures.

\section{Lessons Learned and Implications for the Future \\ Canadian experience}

Canada has now had over a decade of experience with regionalization and some noteworthy patterns are discernible with respect to governance models.

First, there are some very mixed messages on the future of regionalization in Canada. Lewis and Kouri (2004) argued that the future of a regionalized system seems relatively secure in most provinces. Even Ontario, the largest province and the one jurisdiction that has resisted a full model of regionalization now appears to be going down a similar path with the implementation of Local Health Integration Networks (LHINs). The Local Health System Integration Act 2006 established LHINs as not-for-profit corporations that are responsible for planning, integrating and funding local health services in 14 different geographic areas in the province (Gamble and Woolcoot 2006). However, relatively recent policy changes in Prince Edward Island, New Brunswick and Alberta cast serious doubt on the future of regionalization. Regionalization is a two-sided concept in that it can refer to governance and service delivery. At this point in the Canadian evolution, the concerns seem to focus primarily around the competition among regions arising from different governing structures. The focus is now shifting to a patient first approach by eliminating barriers to access that may have been created by regional structures and to ensure maximum health benefits from resources invested.

Second, in all provinces, even those with regional structures, the constitutional responsibility for healthcare has left the primary accountability for the performance of the health system at the provincial level. As Davis (2004) notes "governments can devolve authority for the delivery of healthcare, but they cannot devolve responsibility." This has led to increased attention to new accountability expectations from regional boards, including performance agreements of various types. The recent changes in Prince Edward Island, New Brunswick and Alberta are placing more of the accountability at the provincial level. 
Third, there has been an ongoing tension in provinces with regional systems between accountability to the provincial government and to the communities served. The pendulum has swung towards the province with various forms of performance agreements being mandated. Consolidating the number of regions and concurrently limiting the scope of action of regional health authorities have all served to increase provincial control over the health system. The recent changes in Prince Edward Island, New Brunswick and Alberta clearly place more control at the provincial level but in each case Governments have made commitments to put advisory structures in place to ensure community input.

Fourth, the accountability to the provincial government has been further reinforced by the elimination of elected boards in favour of boards appointed by the health minister in all provinces with regional systems. Furthermore, in most provinces there are explicit requirements in legislation affecting the hiring of CEOs and the expectations on CEOs that have resulted in increasing accountability of CEOs to the provincial government. Ostry (2006) concludes that in the process of regionalization and re-regionalization in Canada there has been a reduction in accountability between the federal government and the provinces, an erosion of local decision-making and an increased level of provincial control.

At the national level, the federal government has continued to play a significant role in funding the system with major financial injections through the 2003 First Ministers' Accord on Health Care Renewal and the 2004 First Ministers' Ten Year plan. However, this increased level of federal funding has not significantly enhanced the role of the federal government in effecting health system change. While attempts have been made to achieve more coordination and consistency among the provinces in areas like waiting times, pharmaceutical policy and home care, federal leadership continues to be at the high policy and directional level, with few levers to effect real change. The emerging model to advance new initiatives in key priority areas has been for the fed$\mathrm{eral} / \mathrm{provincial/territorial} \mathrm{governments} \mathrm{to} \mathrm{create} \mathrm{new} \mathrm{national} \mathrm{structures} \mathrm{(e.g.,} \mathrm{Canada}$ Info way, Canadian Blood Services, Canadian Institute for Health Information, Canadian Patient Safety Institute and the Health Council of Canada [2005]).

\section{Australian experience}

The experience in Australia illustrates an increased centralization of decision-making at the state level, with increasing degrees of intervention by the Commonwealth government. While several states introduced forms of regionalization, in reality it is in the State of New South Wales where there has been a long-term, sustained effort to deliver services through regional structures with regionally based governance. However, in 2004, after nearly two decades of experience with different iterations of this model in New South Wales, regional boards were abolished. 
The more prominent feature on the Australian scene, compared with Canada, is the involvement of the Commonwealth government. The direct responsibility for family physicians, private specialist physician funding, overall physician policy, pharmaceuticals and aged care taken by the Commonwealth, and the increasingly robust nature of the five-year Health Agreements with the states, have influenced healthcare decision-making considerably.

\section{Future implications}

As of 2006, Canada and Australia have different patterns of governance for health services delivery, but there are very evident centralizing tendencies in both systems. While this paper has focused largely on the evolution at the provincial/state levels, active debate continues in both countries over the role of the central (federal/ Commonwealth) governments. In Australia, the federal-state divide has long been a source of vigorous discussion. This debate has become much more prominent in Australia with the recent work of Podger (2006a,b), who recommends that the Commonwealth government assume greater financial responsibility for the system as both funder and purchaser. In Canada, the federal-provincial/territorial debate has focused instead on the need for more coordination, common standards and consistent healthcare access policies.

The overall picture at the provincial/state level is of a mounting tendency towards centralization. This trend is pronounced in Australia, where regional boards no longer exist in several states. The central question in Australia at this time is whether this centralizing tendency will now go beyond the individual states and territories to the Commonwealth government itself. It is a logically plausible, but politically turbulent, possibility for the Commonwealth to assume much more responsibility for the whole health system (Podger 2006a,b); but there is disagreement (Braithwaite 2006). In Canada, boards continue to operate, but as noted there are increased signs of a shift in the pendulum of power from boards back to the provincial governments. The reality is that both health systems have moved gradually to increased accountability and centralized control.

Australian detractors have lamented, as have their Canadian counterparts, that local decision-making has been eroded as a consequence. This situation has developed for a number of reasons, including the centralization tendencies in regionalization processes, the dominance of ministerial appointees rather than community members on boards and the surrendering of local hospital-based/health program decision-making to larger regional interests.

Striving for better governance in both countries will require greater attention to principles and evidence to guide future decision-making. Much rhetoric has been mobilized in prior eras, and the underlying motives for change have not always been 
transparent. Continuous fiddling with structural arrangements or regional boundaries is not necessarily destined to advance efficiency or quality of care. It often creates disruption and anxiety (Braithwaite et al. 2006; Fulop et al. 2002). The available evidence suggests that mergers can lead to disaffected stakeholders and that cost-effectiveness is not realized automatically (Dwyer and Leggat 2002). While increased efficiency is the goal, it is not clear that incremental benefits are being realized. Large organizations, especially complex ones like health services, can become unwieldy. Without using a more evidence-based approach to change, decision-makers run the risk of inducing more uncertainty for providers and the public, as well as destabilizing the health system and further demoralizing healthcare workers.

There are difficulties in coming to definitive conclusions on the results of regionalization. While much has been written in Canada, there is still little conclusive evidence on regionalization's effects. Leatt and Nickoloff (2001) note that "little has been done in most jurisdictions to evaluate the success of regionalization." In reviewing the Saskatchewan situation, Marchildon (2005) observes that an assessment of the impact of regionalization on shifting expenditures for acute care is difficult to make and that a multifaceted research agenda is needed. Lawson and Evans (1992) evaluated the trends in regionalization in New South Wales. They argue that the establishment of Area Health Services had been successful, and better coordination, more focused responsibilities and improved efforts to rationalize duplication were the major benefits. While there are many assertions that the Canadian experience points to better continuity of care, less duplication of services and greater ability to organize integrated health strategies, evidence to support these assertions is still to be obtained. Marchildon (2006) observes that no comprehensive, systematic study of the impact of regionalization has yet been carried out.

While both the Canadian and Australian health systems have undergone significant structural reforms over the past two decades, many challenges continue in terms of rising costs, quality of care, appropriate access and the morale of the healthcare workforce. Increasingly, these issues are being acknowledged to demand far more than a structural or governance solution. Braithwaite (2006) argues that greater attention needs to be paid to the cultural frame of reference, which can help to explain and change behaviours and practices. The argument is that we must go beyond the structural preoccupation typical of reformers and begin to look more profoundly at the needs of patients and clinicians.

Perhaps we are observing an international trend underpinned by some core realities. At the heart of governance in healthcare are the leadership and management of an extremely complex undertaking. Health systems embody a rich mix of clinicians, support staff, managers, policy makers and politicians dealing with life-and-death issues in a context of rising costs and increasing technology. All these forces influence what is the core of the system: the patient-clinician interaction. Put this all together and you 
have governance problems that are likely to be more intricate and sensitive than you will find in any other sector or human undertaking.

Correspondence may be directed to: Dr. Don Philippon, Professor, Strategic Management and Health Policy School of Business, University of Alberta, Edmonton, AB T6G 2J9; tel.: 780-4926476; e-mail: don.philippon@ualberta.ca.

\section{REFERENCES}

Alberta Health and Wellness. Retrieved July 3, 2008. <http://www.health.alberta.ca/regions, 2008>.

Australian Institute of Health and Welfare (AIHW). 2004. Australia's Health. Canberra: Author.

Braithwaite, J., M. Westbrook, D. Hindle, R. Iedema and D. Black. 2006. “Does Restructuring Hospitals Result in Greater Efficiency? An Empirical Test Using Diachronic Data." Health Services Management Research 19(1): 1-12.

Braithwaite, J. 2006. "Response to Podger's Model Health System for Australia (Part 1 and Part 2)." Asia Pacific Journal of Health Management 1(2): 15-21.

Crichton, A. 1998. Children of a Common Mother: A Comparative Analysis of the Development of the Australian and Canadian Health Care Systems to 1995. Australian Studies in Health Service Administration No. 83. Sydney: University of New South Wales.

Davis, J. 2004. “Let Regionalization Continue to Evolve." Healthcare Papers 5(1): 50-55.

Decter, M.B. 2000. Four Strong Winds: Understanding the Growing Challenges to Health Care. Toronto: Stoddart.

Dwyer, J. 2004. "Regionalization: Are Even the Flaws Quintessentially Canadian?" Healthcare Papers 5(1): 81-87.

Dwyer, J. and S.G. Leggat. 2002. "Innovation in Australian Hospitals." Australian Health Review 25(5): 19-31.

Fulop, N., G. Protopsaltis, A. Hutchings, A. King, P. Allen, C. Normand and R. Walters. 2002 (August). "Process and Impact of Mergers of NHS Trusts: Multicentre Case Study and Management Cost Analysis." British Medical Journal 325: 246.

Gamble, N. and F. Woolcott. 2006 (November). "Working Together for Better Health." Presentation to the Probus Club of Woodstock, Ontario.

Government of South Australia. 2003 (April). Better Choices, Better Health: Final Report of the South Australian Generational Health Review. Adelaide: SA Department of Health.

Government of Victoria. 2000. Ministerial Review of Health Care Networks. Final Report.

Melbourne: Victoria Department of Human Services.

Gray, G. 1991. Federalism and Health Policy: The Development of Health Systems in Canada and Australia. Toronto: University of Toronto Press.

Green, D. and L. Cromwell. 1984. Mutual Aid or Welfare State: Australia's Friendly Societies. Sydney: Allen \& Unwin. 
Health Council of Canada. 2005. Health Care Renewal in Canada: Accelerating Change. Ottawa: Author.

Horsburgh, M.D. 1976. "Some Issues in the Government Subsidy of Hospitals in New South Wales, 1858-1910." Medical History 21(2): 161-81.

Houston, C.S. 2002. Steps on the Road to Medicare: Why Saskatchewan Led the Way. Montreal: McGill-Queen's University Press.

Inglis, K.S. 1980. Hospital and Community: A History of the Royal Melbourne Hospital. Melbourne: Nelson.

Jamieson, J. 1980. Commission of Inquiry into the Efficiency and Administration of Hospitals: Report (3 volumes). Canberra: Australian Government Publishing Service.

Kouri, D. 2002 (October). “Is Regionalization Working?” Canadian Healthcare Manager. Retrieved June 24, 2008. <http://www.chmonline.ca/issue/article.jsp? content=20021001_110004_1004>.

Lawson, J. and A. Evans. 1992. "The Successful Development of Decentralised Health Service Management: An Evaluation of Area Health Services in New South Wales." Australian Health Review 15(3): 237-47.

Leatt, P. and B.J. Nickoloff. 2001. Managing Change: Implications of Current Health Reforms on the Hospital Sector. OHA Discussion Paper. Toronto: Ontario Hospital Association.

Levine, D. 2004. "Regionalization: An Opportunity for Improving Management." Healthcare Papers 5(1): 46-54.

Lewis, S. and D. Kouri. 2004. "Regionalization: Making Sense of the Canadian Experience." Healthcare Papers 5(1): 12-30.

Lewis, S.J., D. Kouri, C.A. Estabrooks, H. Dickinson, J.J. Dutchak, J.I. Williams, C. Mustard and J. Hurley. 2001 (February). "Devolution to Democratic Health Authorities in Saskatchewan: An Interim Report." Canadian Medical Association Journal 165(3): 343-47.

Lomas, J. 1997 (March). “Devolving Authority for Health Care Services in Canada's Provinces: 4. Emerging Issues and Prospects." Canadian Medical Association Journal 156(6): 817-23.

Maioni, A. 2004. "Roles and Responsibilities in Health Care Policy." In G.P. Marchildon, T. McIntosh and P.-G. Forest, eds., The Governance of Health Care in Canada: The Romanow Papers (vol. 3). Toronto: University of Toronto Press.

Marchildon, G.P. 2005 (November). "Regionalization and Health Services Restructuring in Saskatchewan." Conference paper. Kingston, ON: Queen's University.

Marchildon, G.P. 2006. Health Systems in Transition: Canada. Toronto: University of Toronto Press.

McCoppin, B. 1974. The Hospital System in Victoria: Administration and Policymaking. MA Thesis, La Trobe University, Melbourne, Australia.

Murphy, M."'Transformational Changes Put Patients First, "Press Release, Communications New Brunswick, March 8, 2008.

NSW Health. 2004a. Planning Better Health Reforms. Sydney: Department of Health.

NSW Health. 2004b. Area Health Advisory Councils. Sydney: Department of Health.

Ontario Hospital Association (OHA). 2002 (January). Regional Health Authorities in Canada:

Lessons for Ontario. Toronto: Author. 
Ostry, A. 2006. Change and Continuity in Canada's Health Care System. Ottawa: CHA Press. PEI System Evaluation Project. 1997 (June). A Guide to System Evaluation: Assessing the Health and Social Services System in PEI. Charlottetown: Department of Health and Community Services System.

Philippon, D.J. and S.A. Wasylyshyn. 1996 (Spring). “Health Care Reform in Alberta." Canadian Public Administration 39(1): 70-84.

Pineault, R., P.A. LaMarche, F. Champagne, A. Contandriopoulos and J. Denis. 1993."The Reform of the Quebec Health Care System: Potential for Innovation?" Journal of Public Health 14(2): 198-219.

Podger, A. 2006a. "A Model System for Australia, Part 1: Directions for Reform of the Australian Health System." Asia Pacific Journal of Health Management 1(1): 10-16.

Podger, A. 2006b. "A Model Health System for Australia, Part 2: What Should a (Single) Commonwealth Funded Public Health System Look Like?” Asia Pacific Journal of Health Management 1(2): 8-14.

Premier's Commission on Future Health Care for Albertans. 1989. The Rainbow Report: Our Vision for Health, Volume II. Edmonton: Author.

Roemer, R. 1955. History of Rural Local Government in Saskatchewan: A Technical Reference Document to the Commission's Official Report on Rural Roads and Local Government. Report of the Saskatchewan Royal Commission on Agriculture and Rural Life. Regina: Queen's Printer.

Riley, Dave, Deputy Minister, Prince Edward Island Department of Health. Interview, August 30, 2005.

Saskatchewan Commission on Directions in Health Care. 1990. Future Directions for Health Care in Saskatchewan. Regina: Author.

Scotton, R.B. and C.R. Macdonald. 1993. The Making of Medibank. Australian Studies in Health Service Administration No. 76. Sydney: University of New South Wales, School of Health Services Management.

Stoelwinder, J. and R. Viney. 2000."Tale of Two States: New South Wales and Victoria." In A. Bloom, ed., Health Reform in Australia and New Zealand. Melbourne: Oxford University Press.

Taylor, M.G. 1978. Health Insurance and Canadian Public Policy: The Seven Decisions That Created the Canada Health Insurance System. Montreal: McGill-Queen's University Press. 